\title{
Optical Structural Design using Gaussian Optics for Multiscale Gigapixel Camera
}

\author{
Cheon-Seog $\operatorname{Rim}^{\dagger}$ \\ Department of Photonics and Sensors, Hannam University, 133 Ojeong-dong, Daedeok-gu, Daejeon 306-791, Korea
}

(Received August 14, 2013; Accepted October 28 2013)

\begin{abstract}
It was reported in Nature and the Wall Street Journal on June 20th, 2012 that scientists at Duke university have developed a gigapixel camera, capable of over 1,000 times the resolution of a normal camera. According to the reports, this super-resolution camera was motivated by the need of US military authorities to surveil ground and sky. We notice the ripple effect of this technology has spread into the area of national defense and industry, so that this research has started to realize the super-resolution camera as a frontier research topic. As a result, we can understand the optical structure of a super-resolution camera's lens system to be composed of a front, monocentric objective of a single lens plus 98 rear, multiscale camera lenses. We can also obtain the numerical ranges of specification factors related to the optical structure, such as the diameter of the aperture, and the focal length.
\end{abstract}

Keywords: Gigapixel camera, Multiscale, Monocentric objective, Microcamera lens

OCIS codes: (080.0080) Geometric optics; (080.2468) First-order optics; (080.2740) Geometric optical design; (080.3620) Lens system design

\section{상분할 방식의 기가픽셀 카메라를 위한 가우스 광학적인 구조설계 \\ 임천석 ${ }^{\dagger}$}

한남대학교 광·센서공학과

(ㅇ) 306-791 대전광역시 대덕구 오정동 133 번지

(2013년 8월 14일 받음, 2013년 10월 28일 게재 확정)

\begin{abstract}
작년 6 월 20 일, 기존의 일반 카메라에 비해 화질이 1,000 배 이상인 초고분해능의 기가픽셀카메라가 미국 듀크대의 과학자들에 의해 네이처에 보고되었고 이를 월스트리트 저널이 보도했다. 보도에 따르면, 이 카메라는 미군부의 필요에 의해 공중 및 지상 배치감시를 목적으로 개발되었다는 것이다. 이 기술은 향후 국방과 산업분야의 전반에 걸쳐서 기술·경제적인 파급효과가 매우 클 것으로 예상되기 때문에 국내에서도 시급히 개발에 착수할 필요가 있다고 판단된다. 이에 본 연구에서는 슈퍼 분해능을 갖는 상분할 방식의 기가픽셀 카메라를 구현하기 위한 전초작업으로써 카메라 렌즈시스템의 광학적인 구조를 고찰하였고 더불어 구조 와 관련된 렌즈사양 값들의 범위를 계산해 내었다.
\end{abstract}

Keywords: 기가픽셀카메라, 상분할, 공심대물렌즈, 마이크로 카메라렌즈

OCIS codes: (080.0080) Geometric optics; (080.2468) First-order optics; (080.2740) Geometric optical design; (080.3620) Lens system design

\section{I. 서 론}

작년 6월 20일 미국 듀크대의 과학자들이 사진을 찍고 화 면을 줌인(zoom-in) 하면 아주 극도로 미세한 부분까지 선명 한 화상을 얻어낼 수 있는 슈퍼 분해능의 기가픽셀 카메라를 개발했다고 네이처에 ${ }^{[1]}$ 발표하였고 이를 월스트리트저널이 ${ }^{[2]}$ 보도했다. 픽셀은 $\mathrm{CCD}$ 와 $\mathrm{CMOS}$ 와 같은 전자필름 상에서 디 지털 이미지를 구성하는 최소 단위의 면적을 나타내고 실제
로는 가로세로의 길이가 마이크로미터 $(\mu m)$ 정도의 단위로 된 정사각형의 면적이다. 통상의 디지털 카메라들은 픽셀크 기보다 훨씬 큰, 말하자면 10 배 정도의, 상당한 잔류수차를 가지고 있고 대개 800 만 화소에서 4천만 화소 사이의 픽셀 들로 구성되어 있다. ${ }^{[3]}$ 보도에 따르면, 듀크대의 과학자들은 미 군부의 필요에 의해 공중·지상의 배치감시를 목적으로 이 카메라를 개발하였고 미 국방부 산하 국방고등연구프로 젝트국(DARPA)으로부터 2,500만 달러를 지원받았다는 것이다.

${ }^{\dagger}$ E-mail: csrim@hnu.kr

Color versions of one or more of the figures in this paper are available online. 
연구책임자인 듀크대의 브래디(D. J. Brady) 박사는, 실제로 이 카메라로 시애틀의 도심을 찍어본 결과, 600 미터 떨어진 주차장의 입구와 출구 표지판을 읽을 수 있었다고 보고했다..$^{[2-3]}$

한편, 지금도 기가픽셀 카메라가 존재하기는 한다. 예를 들 면, 하와이의 팬 스타스(Pan-Starrs) 망원경도 기가픽셀 카메 라로 분류될 수 있다. 하지만 초고해상도에 비해 아주 협소 한 화각을 갖고 있어 우주관측용으로만 적당할 뿐이고 군사 적 목적의 공중지상의 배치감시를 위해서는 적합하지 않다. 반면, 듀크대의 기가픽셀 카메라는 미국 동부와 서부 전체를 한 장의 사진에 찍으면서도 개별도시와 공원 기념물 등을 줌 인해 자세히 볼 수 있다..$^{[1-3]}$

듀크대는 기가픽셀 카메라를 구현하기 위해 상분할 방식의 광학구조를 취했다. 상분할(multiscale) 방식의 광학구조란 통 상의 카메라에서 얻어지는 하나의 전체 화상을 가로세로 균 등 분할(예, $5 \times 5$ 로 분할)하여 분할된 부분화상의 개수만큼 카메라를 배치하고 각각의 카메라로부터 분할상(sectored image)을 얻어내는 것을 말한다. ${ }^{[4-6]}$ 설명처럼, 상분할 방식은 광학 구조적으로 기존의 메가픽셀급의 이미지 센서를 사용 하여 기가픽셀급의 해상도를 구현할 수 있는 가장 단순하고 효과적인 방법이고 개개의 분할된 화상에 대해서도 회절한 계에 근접하게 수차를 보정할 수 있는 방법이기도 하다. 그 림 1 은 통상의 카메라와 상분할 방식 간의 전형적인 비교그 림이다. 참조하기 바란다. 그림 1 의 (b)를 살펴보면 상분할을 위해 공통의 단일렌즈(대물렌즈)로 먼저 전체 상을 얻고 이 를 다시 다수의 마이크로 카메라렌즈로 분할하는 구조로 되 어 있다. 듀크대의 기가픽셀 카메라도 전방에 직경 $6 \mathrm{~cm}$ 의 볼 모양의 대물렌즈와 각기 14 메가 픽셀의 이미지센서를 장 착한 98 개의 마이크로카메라로 구성되어 있다. ${ }^{[1-3]}$ 단일의 전 체 상을 각기 14 메가 픽셀인 98 개의 마이크로 카메라로 분 할하기 때문에 전체 픽셀은 약 1.4 기가 픽셀이 된다. 즉, 98 개의 마이크로카메라를 사용하면 14 메가 픽셀의 이미지센 서로 1.4 기가 픽셀을 얻을 수 있다는 것이다.

브래디 박사는 여기서 한 발 더 나아가 2012년 말까지는 10 기가 픽셀의 컬러사진을 찍을 수 있는 카메라를 개발할 것이며, 이어서 50 기가 픽셀을 찍을 수 있는 카메라도 개발 할 예정이라고 밝혔다. ${ }^{[2-3]}$ 이와 같은 슈퍼 분해능을 갖는 초

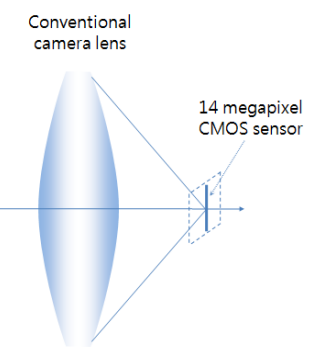

(a)

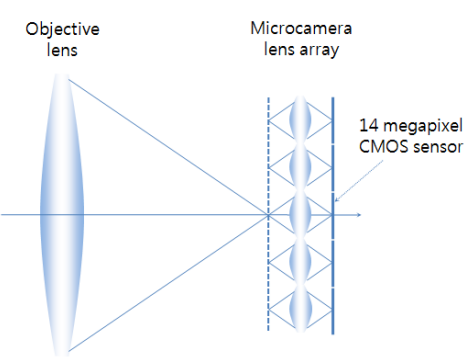

(b)
FIG. 1. Schematic diagrams of comparison between two types of images. (a) image by conventional camera lens, (b) image by $5 \times 5$ two-level multiscale camera lens.
고화질의 카메라는 국방과 산업분야에 걸쳐서 기술 및 경제 적인 파급효과가 매우 클 것으로 예상되므로 국내에서도 시 급히 개발에 착수해야 할 것으로 판단된다. 이를 위한 전초 작업으로써, 본 연구에서는 먼저 상분할 방식의 기가픽셀 카 메라에 대한 광학적인 구조를 이해하고자 하며 이로부터 광 학구조를 이루는 렌즈의 사양 값들을 계산해 내고자 한다. 본 연구의 목표를 달성하기 위해 앞으로 전개될 본문에서는 3 개의 장에 걸쳐 주제별로 탐구를 진행하였다. 3 개의 탐구주 제는 다음과 같다. (1) 기가픽셀 카메라를 구현하기 위한 분 해 가능한 스폿(spot)의 수와 정보효율계수 (2) 전방의 대물 렌즈에 대한 구조설계 (3) 후방의 상분할 카메라렌즈에 대한 구조설계.

\section{II. 기가픽셀 카메라를 구현하기 위한 분해 가능한 스폿의 수와 정보효율계수}

기가 픽셀 카메라렌즈를 구현하기 위해서는 먼저 분해 가 능한 스폿의 수와 렌즈와의 상관관계를 탐구할 필요가 있다. 회절한계성능을 가지는 렌즈에 대해서, 에어리 원반(Airy disk)의 직경 $(\sigma)$ 은 다음 식 (1)로 주어지고 상의 직경 $(D)$ 은 다음 식 (2)로 주어진다. ${ }^{[7-8]}$

$$
\sigma=2.44 \lambda f_{\#}=2.44 \lambda\left(f^{\prime} / A\right)
$$

$$
D=2 f^{\prime} \tan (F O V / 2)
$$

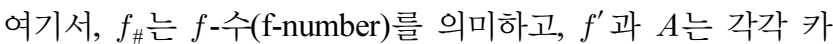
메라렌즈의 초점거리와 입사동의 직경을 나타낸다. 그리고 $F O V$ 는 카메라렌즈로 촬영할 수 있는 화각(field of view)의 최대크기를 나타낸다.

그러면 식 (1)과 (2)로부터 회절한계성능을 가지는 렌즈가 (스폿의 겹침 없이) 분해할 수 있는 스폿의 최대개수 $\left(N_{\max }\right)$ 는 다음 식 (3)으로 주어진다. 식 (3)은 회절한계성능을 가지 는 렌즈에서의 스폿의 수를 나타내므로 수차가 이보다 크다 면 그 수 $(N)$ 는 당연히 줄어들게 된다. 이를 관계식으로 표현 하고 수치적으로 정량화하기 위해 분해할 수 있는 스폿의 개 수와 수차와의 상관관계를 나타내는 $\gamma$ 라는 정보효율계수 (coefficient of information efficiency)를 도입하자. ${ }^{[5]}$ 다음 식 (4)와 (5)를 참조하기 바란다. 그러면 스폿의 개수와 수차와 의 상관관계를 나타내는 매개인자인 $\gamma$ 는 0 에서 1 사이의 값 을 갖게 된다.

$$
\begin{aligned}
N_{\max } & =\frac{\pi(D / 2)^{2}}{\pi(\sigma / 2)^{2}}=\frac{\pi f^{\prime 2} \tan ^{2}(F O V / 2)}{\pi 1.22^{2} \lambda^{2} f^{\prime 2} / A^{2}} \\
& =\frac{0.67 A^{2}}{\lambda^{2}} \tan ^{2}\left(\frac{F O V}{2}\right)
\end{aligned}
$$




$$
\begin{aligned}
& N=\left\{\frac{0.67 A^{2}}{\lambda^{2}} \tan ^{2}\left(\frac{F O V}{2}\right)\right\} \times \gamma \\
& \gamma=\frac{N \lambda^{2}}{0.67 A^{2} \tan ^{2}\left(\frac{F O V}{2}\right)}
\end{aligned}
$$

한편, 일반적으로 임의의 렌즈계가 주어지면, 기하광학적 인 광선추적에 의해서 수차가 있는 스폿의 크기를 계산할 수 있다. 식 (1)에 에어리 원반의 직경 $(\sigma)$ 이 주어졌는데 반경의 크기를 $\omega$ 라 하자. 또, 수차가 있는 스폿의 평균반경(root mean square, RMS)의 크기를 $\rho$ 라고 하자. 그러면 스폿의 반 경크기는, 수차가 있는 스폿반경 $(\rho)$ 이 에어리 원반의 반경 $(\omega)$ 보다 더 작은 회절한계성능을 제외하고, 주로 기하적인 수차에 의해서 결정된다. 종합적으로 다시 애기하면, 스폿반 경에 대한 일반화된 표현식은 회절효과와 수차효과를 동시 에 고려한 복합적인 식으로 주어져야 한다는 것이다. 다음 식 (6)은 스폿의 복합반경(composite radius)에 대한 표현식이다. ${ }^{[5]}$

$$
R_{c}=\sqrt{\omega^{2}+\rho^{2}}=\sqrt{\left(1.22 \lambda f_{\#}\right)^{2}+\rho^{2}}=\sqrt{\frac{3}{2} \lambda^{2} f_{\#}^{2}+\rho^{2}}
$$

식 (6)에서 보는 바와 같이 복합반경 $\left(R_{c}\right)$ 은 회절과 수차효 과에 의한 반경을 각각 제곱하여 더한 후 다시 제곱근을 취 하도록 되어 있다. 즉, 복합반경은 수학적으로는 RSS(root sum square)로 주어진다는 것인데 이의 적합성과 타당성에 대해서 논의해 보자. (1) 수차가 있는 스폿의 평균반경이 에 어리 원반의 평균반경보다 훨씬 크면, 즉, $\omega \ll \rho$ 이면 복합 반경은 $R_{c} \approx \rho$. (2) 기하적인 수차가 없거나 에어리 원반에 비해서 아주 작다면, 즉, $\omega \approx 0$ 이면 복합반경은 $R_{c} \approx \omega$. (3) $\rho=10 \omega$ 이면 $R_{c} \approx 10 \omega$. 수차에 의한 효과가 압도적으로 복 합반경을 결정함. (4) $\rho=\omega$ 이면 $R_{c} \approx 1.4 \omega$. 회절과 수차효 과가 동시에 복합반경에 영향을 미침. (5) $\rho=2 \omega$ 이면 $R_{c} \approx 2.2 \omega$. 수차반경이 회절반경의 두 배만 되어도 복합반경 은 주로 수차효과에 의해 결정됨. 이상과 같이 5 가지 경우에 대한 분석적인 취급으로부터 복합반경은 $\mathrm{RSS}$ 로 잘 표현되어 질 수 있다고 결론내릴 수 있다.

결과적으로 수차가 있는 렌즈가 분해할 수 있는 스폿의 개 수 $(N)$ 는 상의 면적을 복합스폿의 면적으로 나눈 값이 된다. 식 (3)과 식 (6)을 참조하기 바란다.

$$
N=\frac{\pi(D / 2)^{2}}{\pi\left(\frac{3}{2} \lambda^{2} f_{\#}^{2}+\rho^{2}\right)}=\frac{D^{2}}{4\left(\frac{3}{2} \lambda^{2} f_{\#}^{2}+\rho^{2}\right)}
$$

식 (7)을 식 (5)에 대입하면, 다음 식 (8)을 얻을 수 있다. 또 $f_{\#}=f^{\prime} / A$ 과 식 (2)을 사용하여 식 (8)의 분모를 정리하면, 첫째 항은 약 1 의 값을 갖게 되고 둘째 항은 $\left\{\rho /\left(1.22 \lambda f_{\#}\right)\right\}^{2}$ 값을 갖게 되어, 결국 식 (9)로 축약된다.

$$
\begin{aligned}
\gamma & =\frac{N \lambda^{2}}{0.67 A^{2} \tan ^{2}(F O V / 2)}=\frac{\lambda^{2}}{0.67 A^{2} \tan ^{2}(F O V / 2)} \times \frac{D^{2}}{4\left(\frac{3}{2} \lambda^{2} f_{\#}^{2}+\rho^{2}\right)} \\
& =\frac{1}{\left\{\frac{4 \times 0.67 \times \frac{3}{2} A^{2} \tan ^{2}\left(\frac{F O V}{2}\right) \lambda^{2} f_{\#}^{2}}{\lambda^{2} D^{2}}\right\}+\left\{\frac{4 \times 0.67 \times A^{2} \tan ^{2}\left(\frac{F O V}{2}\right) \rho^{2}}{\lambda^{2} D^{2}}\right\}} \\
\gamma & =\frac{1}{1+\left(\frac{\rho}{1.22 \lambda f_{\#}}\right)^{2}}=\frac{1}{1+\left(\frac{\rho}{\omega}\right)^{2}}
\end{aligned}
$$

식 (9)의 의미를 파악해 보자. (1) 기하광학적인 수차가 제 로이면, 즉, $\rho=0$ 이면 $\gamma=1$. (2) 에어리 원반에 비해 수차 가 있는 스폿의 반경이 매우 크면, 즉, $\rho \gg \omega$ 이면 $\gamma \rightarrow 0$. (3) $\rho=\omega$ 이면 $\gamma=1 / 2$. 에어리 원반의 반경과 같을 정도로 수차의 평균값이 발생하면, 렌즈로 구현할 수 있는 정보량인 분해할 수 있는 스폿의 개수가 반으로 급격히 줄어들게 된 다. (4) $\rho=2 \omega$ 이면 $\gamma=1 / 5$. (5) 식 (9)을 수치적으로 조밀하 게 계산하여 수차에 의해서 정보효율이 감소하는 경향을 한 눈에 알아볼 수 있도록 그림 2에 나타내었다. 참조하기 바란다.

그림 2에서 보여 지는 봐와 같이, 수차에 의한 스폿의 반 경크기가 커지면 렌즈로 구현할 수 있는 정보량인 스폿의 개 수(픽셀의 개수)는 급격히 줄어들게 된다. 즉, 에어리 원반의 5 배 정도의 수차크기만으로도 수차가 없을 때와 비교할 때 거의 $1 / 25$ 배로 정보량이 줄어든다. 결론적으로 애기하면, 잔 류수차(residual aberration)가 커서 회절한계성능과 거리가 먼 통상의 디지털 카메라렌즈로는 기가픽셀카메라를 구현할 수 없고 기가픽셀카메라를 구현하기 위해서는 회절한계성능 이하로 수차를 최대한 줄인 각각의 98 개의 마이크로 카메라 렌즈가 필요하다는 것이다. 또, 98 개의 마이크로 카메라렌즈 는 전방의 대물렌즈에서 발생한 수차도 각각의 위치에서 개 별적으로 보상하여 제거해야한다.

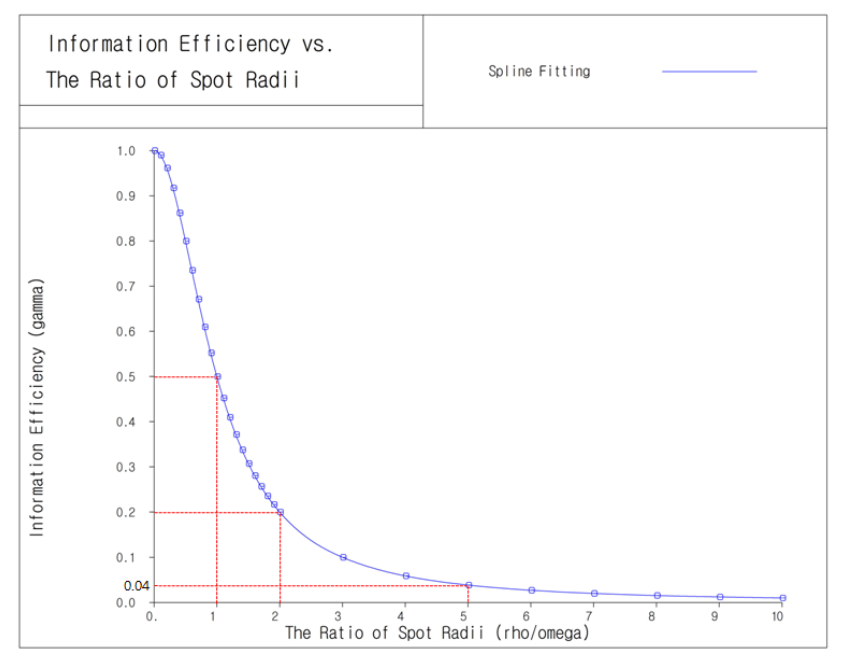

FIG. 2. Information efficiency $(\gamma)$ according to the ratio of spot radii $(\rho / \omega)$ between the aberrated radius $(\rho)$ and the radius of Airy disk $(\omega)$. 


\section{III. 전방의 대물렌즈에 대한 구조설계}

기가픽셀카메라는 상분할 방식의 광학구조로 되어있다. 즉, 상분할(multiscale)을 위해 공통의 단일렌즈(대물렌즈)로 먼 저 전체 상을 얻고 이를 다시 다수의, 말하자면, 98 개의 마이 크로 카메라렌즈로 분할하는 구조라는 것이다. 그림 1의 (b) 를 참조하기 바란다. 그림 1 의 (b)에서 보여 지듯이 본 연구 의 기가픽셀카메라를 위해서는 우선적으로 전방의 대물렌즈 에 대하여 구조설계를 진행해야 함을 알 수 있다. ${ }^{[9-11]}$

그럼, 구체적인 설계논의로 넘어가기 위해 그림 3을 참조 하자. 그림 3에서 살펴보면, 구조적으로 결정되어져야 할 설 계변수는 렌즈의 직경(입사동) $A$ 와 초점거리 $f^{\prime}$ 이다. 렌즈로 구현할 수 있는 스폿의 최대개수와 입사동의 직경과의 관계 는 식 (3)으로부터 주어진다. 스폿의 최대개수는 전방대물렌 즈에 의해 결상된 상이 얼마나 많은 스폿으로 분해될 수 있 는지를 의미하고 이는 곧 상이 몇 개의 픽셀로 구성되는지와 같은 의미가 되기도 한다. 식 (3)에서 식을 구성하는 설계의 기초인자 값들은 브래디 박사의 연구를 참조하여 결정하도 록 한다. $N_{\max }=1.4 \mathrm{G}$ pixels, $F O V=120^{\circ} \times 50^{\circ}, \lambda=0.587$ $\mu \mathrm{m} .{ }^{[1]}$ 그러면 이 수치 값들로부터 다양한 입사동의 직경 $(A)$ 에 대해 가능한 스폿의 최대개수를 계산해 낼 수 있게 된다.

그림 4와 5에 계산결과가 주어진다. 각각 최대 화각 $(F O V)$ $120^{\circ}$ 와 $50^{\circ}$ 를 기준으로 계산되었다. 그림 4 를 보자. 최대 화 각 $120^{\circ}$ 를 기준으로 판단해 보면 입사동의 직경이 $20 \mathrm{~mm}$ 정도는 되어야 전방대물렌즈의 상면에서 1.4 기가 픽셀의 분 해능을 가질 수 있다. 반면 최대 화각이 $50^{\circ}$ 인 그림 5 에서 보면 입사동의 직경이 $60 \mathrm{~mm}$ 는 되어야 1.4 기가 픽셀의 분 해능을 가질 수 있다. 종합해서 보면, $20 \mathrm{~mm}$ 와 $60 \mathrm{~mm}$ 사이 에서 전방대물렌즈의 직경(혹은 입사동의 직경)이 결정된다 는 것이다. 렌즈 분해능에 대한 여유분을 충분히 고려한다면 대물렌즈의 직경 $(A)$ 은 $60 \mathrm{~mm}$ 가 적절할 것으로 보여 진다.

일단, 대물렌즈의 직경 $(A)$ 이 결정되고 나면 식 (1)로부터

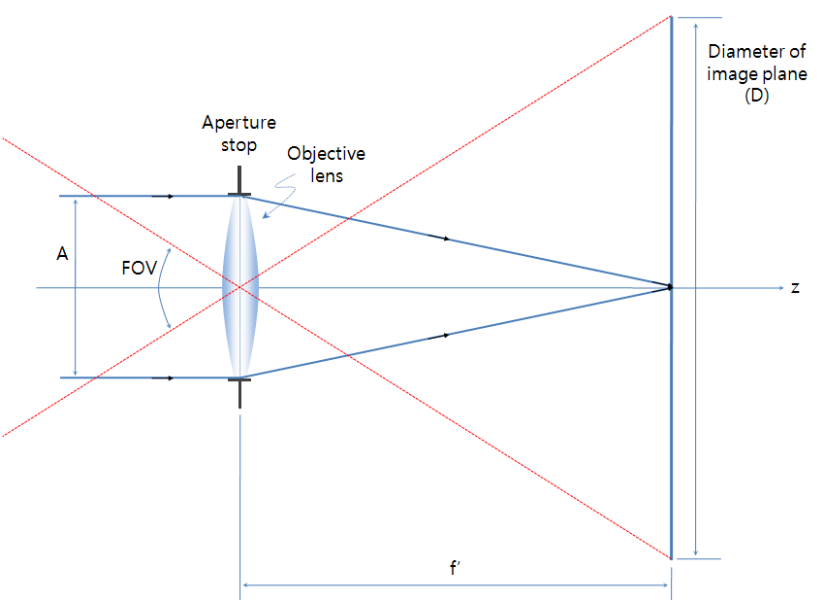

FIG. 3. Schematic diagram of the front objective composed of single lens with the structural design parameters such as the diameter of aperture $(A)$ and focal length $\left(f^{\prime}\right)$.
초점거리를 계산할 수 있다. 하지만 식 (1)에서 보듯이 에어 리 원반의 직경 $(\sigma)$ 값이 결정되어야만 초점거리가 계산되도 록 되어 있기 때문에 에어리 원반의 직경 값에 대한 기준이 필요하다. 이는 단일픽셀의 크기에 대한 정보로부터 설정될 수 있다. 온 세미컨덕터(ON Semiconductor)사의 IBIS4-14K $\mathrm{CMOS}$ 모델을 참조한다. 이 모델은 14 메가 픽셀의 $\mathrm{CMOS}$ 센서로 단일픽셀의 크기가 가로세로 $8 \mu \mathrm{m} \times 8 \mu \mathrm{m}$ 이다. 그러 면 에어리 원반의 직경 $(\sigma)$ 값은 최대 $8 \mu \mathrm{m}$ 을 넘지 않아야 한다. $\sigma$ 값이 $2,4,6,8 \mu \mathrm{m}$ 일 때 그에 대응되는 초점거리 $\left(f^{\prime}\right)$ 값은 그림 6으로 주어진다. 그림 6에서 살펴보면, 전방 대물렌즈의 초점거리는 $84 \mathrm{~mm}$ 에서 $335 \mathrm{~mm}$ 사이에 분포한 다. 만약, 에어리 원반의 직경 값을 픽셀 크기의 반으로 설정 한다면 초점거리는 $168 \mathrm{~mm}$ 가 된다. 즉, 광학적인 스폿의 직

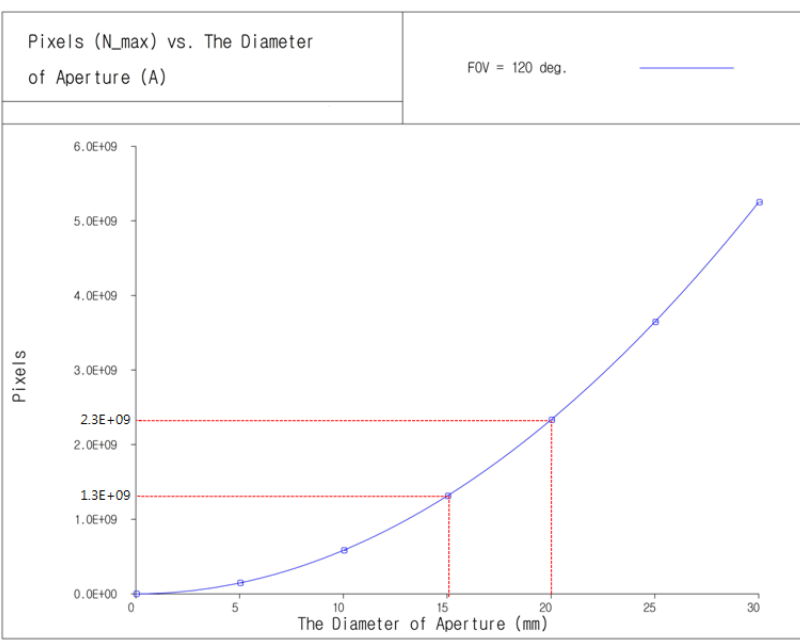

FIG. 4. The number of pixels or resolvable spots on the image plane of the front objective according to the diameter of aperture (A) for $F O V=120^{\circ}$.

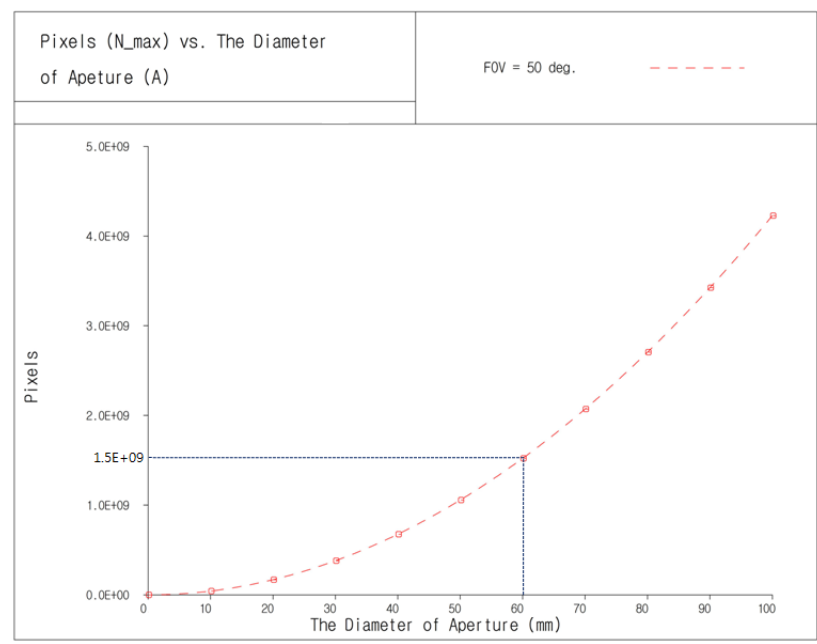

FIG. 5. The number of pixels or resolvable spots on the image plane of the front objective according to the diameter of aperture (A) for $F O V=50^{\circ}$. 


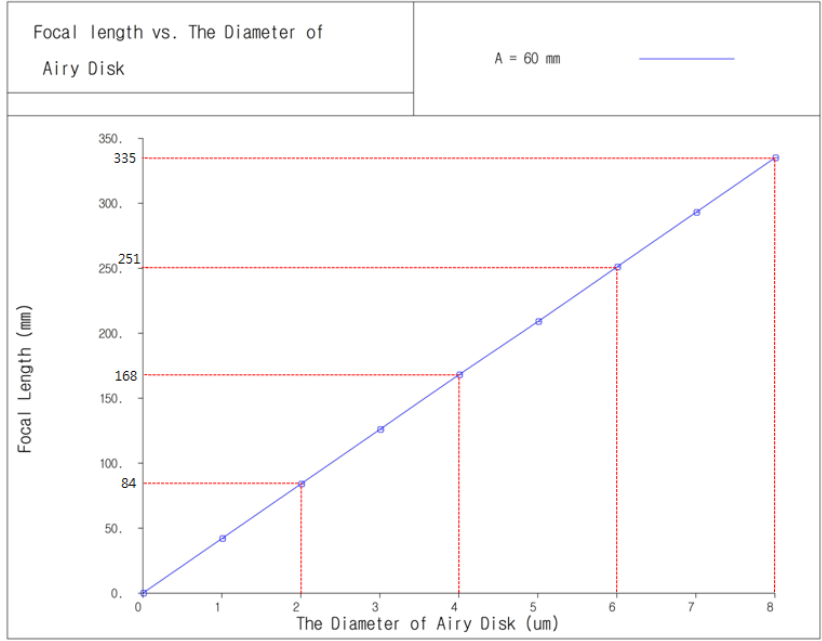

FIG. 6. The range of focal length for the front objective according to the diameter of Airy disk $(\sigma)$.

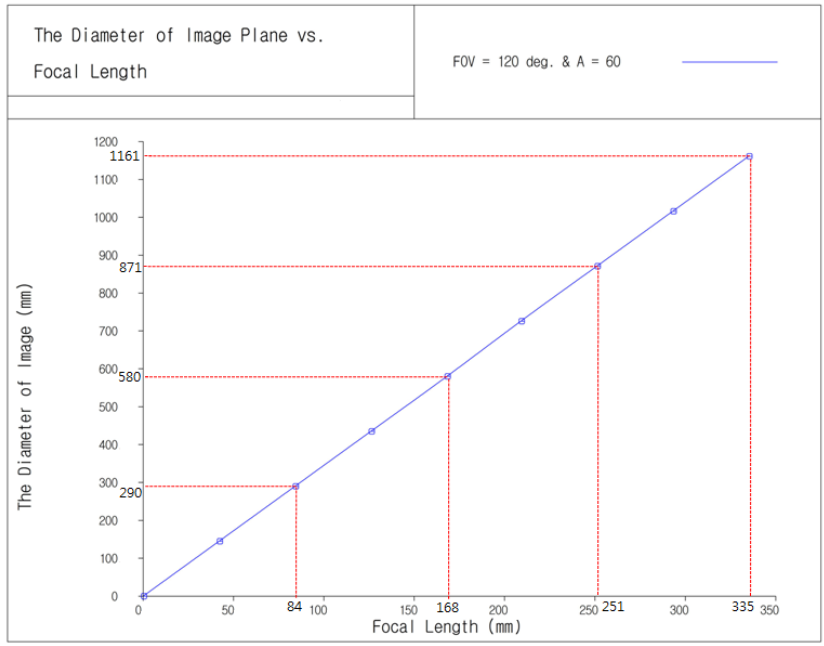

FIG. 7. The diameter of image plane according to focal length of the front objective.

경 값을 픽셀크기에 비해 충분히 작게 가져갈 수 있는 초점 거리 값은 $168 \mathrm{~mm}$ 이하라는 것이다.

초점거리 $\left(f^{\prime}\right)$ 값이 결정되면 이어서 전방대물렌즈의 상면 의 직경 $(D)$ 값이 계산될 수 있다. 식 (2)로부터 상면의 직경 값 $D$ 가 주어진다. 그림 7을 참조하기 바란다. 그림 7에서도 보듯이 초점거리에 비례하여 상의 직경 값이 커지므로 가급 적 짧은 초점거리를 선택하면 카메라 시스템의 전체적인 볼 륨을 줄일 수 있게 된다. 결과적으로 전방대물렌즈의 초점거 리 $\left(f^{\prime}\right)$ 는 시스템의 볼륨과 필요한 광학적인 스폿의 직경 값 에 대한 요건으로부터 $84 \mathrm{~mm}$ 에서 $168 \mathrm{~mm}$ 사이가 적절하다 고 결론지을 수 있다.

한편, 본 연구의 기가픽셀카메라는 화각을 $120^{\circ} \times 50^{\circ}$ 로 설 정하였다. 즉, 전방대물렌즈의 화각이 $120^{\circ} \times 50^{\circ}$ 라는 것이다. 화각이 큰 카메라렌즈에서는 상면이 임의의 곡률로 휘게 되 는 상면만곡수차가 발생하는데, 실제로 상면의 곡률반경 $(R)$

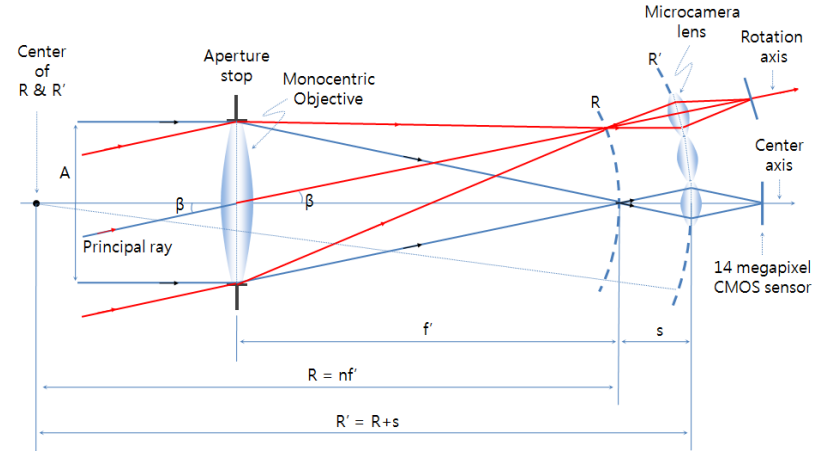

FIG. 8. Schematic diagram of the front monocentric objective with the spherical image surface.

값은 자이델 3 차 수차이론에 의하면 페츠발 합(Petzval sum) 의 역수로 주어진다. ${ }^{[10-11]}$ 결과적으로 상면의 곡률반경 $(R)$ 값 은 전방대물렌즈의 굴절률 $(n)$ 과 초점거리 $\left(f^{\prime}\right)$ 의 곱으로 간단 히 표현된다. 다음 식 (10)을 참조하기 바란다. 식 (10)에서 굴절률 $n$ 는 1.5 로 설정하고 초점거리는 $84 \mathrm{~mm}$ 에서 $168 \mathrm{~mm}$ 범위로 한정하면 이에 대응되는 상면의 곡률반경 값은 126 $\mathrm{mm}$ 에서 $252 \mathrm{~mm}$ 로 주어진다. 그러면, 앞에서 언급되었듯이, 상면의 곡률반경 값으로 인해 상면만곡수차가 발생하므로 이를 광학적으로 보정해 주어야 하지만 본 연구에서는 굳이 광학적으로 보정하지 않고 평면의 상면을 휘어있는 곡면의 상면으로 재설정함으로써 간단히 해결하고자 한다. 이렇게 하면, 마이크로 카메라렌즈와 연계된 전체 렌즈시스템의 구 조적인 관점에 있어서도 이점이 매우 크게 된다. 결론적으로, 상분할 방식의 기가픽셀 카메라의 대물렌즈는 중심점이 하 나인 휘어있는 구면의 상면을 가지도록 설정되면 좋다는 것 이다. 왜냐하면 첫째로는 상면만곡수차를 제거할 수 있어 좋 고 둘째로는 구조적으로 무엇보다도 중요한 이점인데 전방 대물렌즈에 대응되는 98 개의 마이크로 카메라렌즈를 그림 8 에서처럼 주광선의 기울기 $\beta$ 만큼 기울이면 중심축(광축)과 동등한 조건의 광학적인 배치로 변환되기 때문이다. 즉, 이 는 중심축과 동등한 조건으로 회전축의 수차보정도 할 수 있 다는 의미가 되므로 전체 화각에 걸친 복잡한 설계의 문제를 단순화할 수 있게 한다. 이런 이유로 상분할 방식의 기가픽 셀 카메라에서 전방의 대물렌즈는 공심의 대물렌즈 (monocentric objective)가 되도록 채택하는 것이 필수적이다. ${ }^{[12]}$

$$
R=n f^{\prime}
$$

\section{IV. 후방의 상분할 카메라렌즈에 대한 구조설계}

앞 장에서 논의된 것처럼, 상분할 기가픽셀 카메라에서 전 방의 대물렌즈를 공심렌즈로 채택하면 모든 회전축에 대해 광학적으로는 중심축과 동등한 조건이 된다. 즉, 회전축에 대한 설계의 문제도 중심축에 대한 설계의 문제로 단순화시 켜 확장해 나갈 수 있다는 것이다. 그럼, 마이크로 카메라렌 즈의 구조변수에 대해서 설계를 진행해 나가보자. ${ }^{[9-11]}$ 


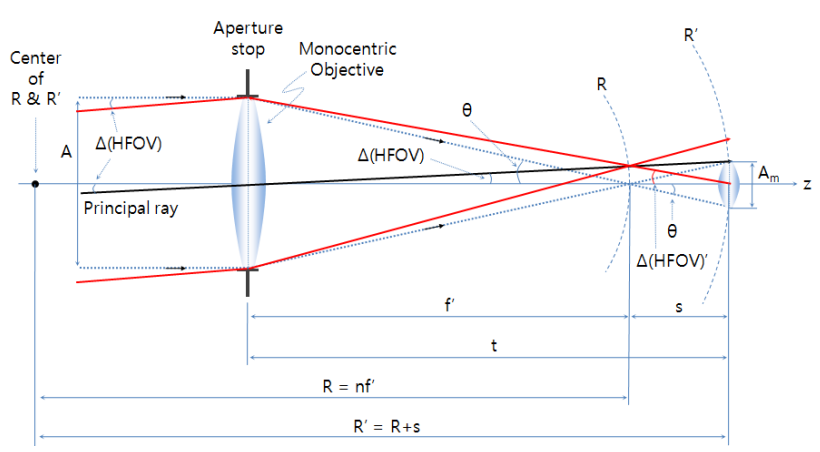

FIG. 9. Schematic diagram of the front monocentric objective and the rear multiscale camera lens to illustrate how to divide $120^{\circ} \times$ $50^{\circ}(F O V)$ into $9^{\circ} \times 6^{\circ}(\triangle(F O V))$.

그림 9를 참조하기 바란다. 그림 9에서 보면, 두 종류의 광 선다발(3개의 광선)이 표현되어 있다. 하나는 물체면의 광축 상에서 출발한 광선다발이고 다른 하나는 물체면의 비축 상 에서 출발한 광선다발이다. 물체면의 비축 상에서 출발한 광 선다발의 반 화각은 $\Delta(H F O V)$ 로 표시되어져 있고 그 두 배 인 화각은 $\Delta(F O V)$ 로 표시되어져 있다. $\Delta(F O V)$ 을 계산해 보자. 우선, IBIS4-14K CMOS 센서의 촬상면적(pixel area)이 $36 \mathrm{~mm} \times 24 \mathrm{~mm}$ 임을 염두에 두자. 이로부터 촬상면적의 가 로세로 비율은 3:2로 주어짐을 알 수 있다. 전체 화각(FOV) 은 $120^{\circ} \times 50^{\circ}$ 로 설정되어져 있고 1.4 기가픽셀을 위해서 98 개의 마이크로 카메라렌즈가 필요한 상황이므로 $\Delta(F O V)$ 값은 $3: 2$ 의 비율인 $9^{\circ} \times 6^{\circ}$ 가 되어야 한다. 왜냐하면, 개개의 마이크로 카메라렌즈의 화각 $\Delta(F O V)$ 가 $9^{\circ} \times 6^{\circ}$ 일 때, $\left(120^{\circ}\right.$ $\left.9^{\circ}\right)$ 개 $\times\left(50^{\circ} / 6^{\circ}\right)$ 개 $=104$ 개로 충분한 개수의 마이크로 카메라 렌즈가 확보되기 때문이다.

$\Delta(\mathrm{FOV})$ 값이 $9^{\circ}$ 가 되면 $\Delta(\mathrm{HFOV})$ 값은 $4.5^{\circ}$ 가 되므로, 먼저, 이를 활용하여 마이크로 카메라렌즈의 직경 $\left(A_{m}\right)$ 을 계 산해 보자. 그림 9를 참조하기 바란다. 그러면 간단한 기하적 인 관계로부터는 식 (11)을 얻을 수 있고 근축광선추적으로 부터는 ${ }^{[10-11]}$ 식 (12)을 얻을 수 있게 된다. 그리고 식 (12)로 부터 식 (13)도 얻게 된다.

$$
\begin{aligned}
& s=\frac{A_{m}}{2 \tan \theta}=\left(\frac{A_{m}}{A}\right) f^{\prime}=t-f^{\prime} \\
& \Delta(H F O V)^{\prime}=\Delta(H F O V)+\frac{A}{2 f^{\prime}} \\
& t=\frac{(A / 2)}{\Delta(H F O V)^{\prime}}=\frac{(A / 2)}{\Delta(H F O V)+\left(A / 2 f^{\prime}\right)}
\end{aligned}
$$

결과적으로 마이크로 카메라렌즈의 직경 $\left(A_{m}\right)$ 값은 식 (13) 을 식 (11)에 대입하여 정리하면 얻을 수 있다. 다음 식 (14) 와 (15)을 참조하기 바란다. 식 (15)는 식 (14)을 정리하여 얻 은 직경 $\left(A_{m}\right)$ 에 대한 최종적인 표현식인데 앞 장에서 구한

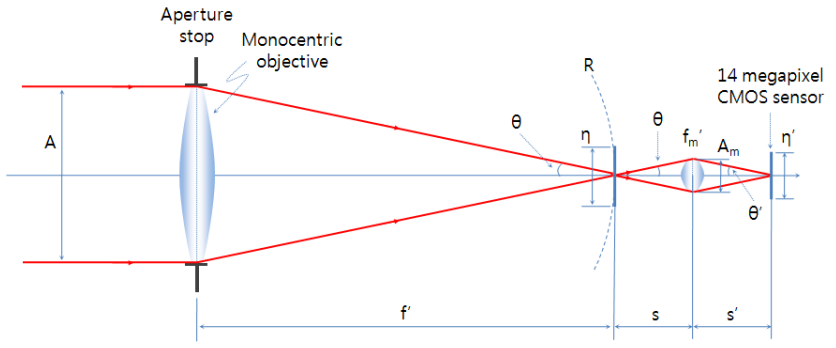

FIG. 10. Schematic diagram of the front monocentric objective and the rear multiscale camera lens to derive Eq. (15) for the diameter of aperture $\left(A_{m}\right)$ and Eq. (16) for focal length $\left(f_{m}{ }^{\prime}\right)$.

다음 값들을 이용하여 수치적으로 계산해 볼 수 있다. $f^{\prime}=$ $84 \mathrm{~mm} \sim 168 \mathrm{~mm}, \Delta(F O V)=9^{\circ}, A=60 \mathrm{~mm}$. 그러면 직경 $\left(A_{m}\right)$ 에 대한 계산 값은 $10.8 \mathrm{~mm} \sim 18.3 \mathrm{~mm}$ 로 주어진다. 한 편, $\Delta(F O V)=6^{\circ}$ 일 때의 직경 값은 $7.7 \mathrm{~mm} \sim 13.6 \mathrm{~mm}$ 로 주어진다. 최종적으로 종합해 보면, 마이크로 카메라렌즈의 구경은 타원형이 되고 $A_{m}\left(f^{\prime}\right)=10.8 \times 7.7(84) \mathrm{mm} \sim 18.3 \times$ 13.6(168) $\mathrm{mm}$ 로 주어진다는 것이다.

$$
\begin{aligned}
& s=\left(\frac{A_{m}}{A}\right) f^{\prime}=\frac{(A / 2)}{\Delta(H F O V)+\left(A / 2 f^{\prime}\right)}-f^{\prime} \\
& \left|A_{m}\right|=\frac{f^{\prime} \Delta(F O V)}{1+f^{\prime} \Delta(F O V) / A}
\end{aligned}
$$

일단 마이크로 카메라렌즈의 직경 값이 계산되고 나면 초 점거리 $\left(f_{m}{ }^{\prime}\right)$ 도 이어서 계산될 수 있다. 그림 10 을 참조하기 바란다. 초점거리에 대한 표현식을 얻기 위해서는 물상 간 $(\eta$ vs. $\left.\eta^{\prime}\right)$ 의 공액 관계식인 배율 식 $\left(M=\theta / \theta^{\prime}\right)$ 을 활용하여 근축 광선추적 관계식 $\left(\theta^{\prime}-\theta=A_{m} / 2 f_{m}{ }^{\prime}\right)$ 을 정리하면 된다. 그 결 과는 식 (16)으로 주어진다. 단, 여기서 $\theta \approx \tan \theta=A / 2 f^{\prime}$ 로 근사하였다.

$$
f_{m}{ }^{\prime}=\left(\frac{A_{m}}{A}\right)\left|\frac{M}{1-M}\right| f^{\prime}
$$

식 (16)을 사용하여 초점거리 $\left(f_{m}{ }^{\prime}\right)$ 를 계산하기 전에 염두에 두어야 할 점은 마이크로 카메라렌즈의 배율이 등배율 $(|M|=1)$ 혹은 축소배율 $(|M|<1)$ 이 되어야 한다는 것이다. 왜냐하면 전방공심렌즈에 의해 분해된 스폿의 개수가 CMOS 센서 면으로 그대로 전달되기 위해서는 물체측과 상측의 수 치구경이 같거나 상측의 수치구경이 더 커야하기 때문이다. 다음 수치 값들을 사용하여 식 (16)을 계산해 보자. $A=60$ $\mathrm{mm}, A_{m}\left(f^{\prime}\right)=10.8(84) \mathrm{mm} \sim 18.3(168) \mathrm{mm}, M=-1$ 또는 $-1 / 2$. 그러면 $M=-1$ 일 때는 $f_{m}{ }^{\prime}\left(f^{\prime}\right)=7.6(84) \mathrm{mm} \sim$ 25.7(168) $\mathrm{mm}$ 로 주어지게 되고, $M=-1 / 2$ 일 때는 $f_{m}{ }^{\prime}\left(f^{\prime}\right)=$ 5.0 (84) $\mathrm{mm}$ 17.1(168) $\mathrm{mm}$ 로 주어지게 된다. 


\section{V. 결 론}

본 논문에서는 상분할 방식의 기가픽셀 카메라를 구현하기 위한 전초작업으로써 카메라 렌즈시스템의 광학적인 구조를 고찰하였고 더불어 구조와 관련된 렌즈의 사양 값들의 범위 를 계산해 내었다. 결론적으로 연구를 통해 얻어진 중요사항 과 결과들은 다음과 같다. (1)정보효율계수 $(\gamma)$ 에 대한 계산으 로부터 잔류수차가 큰 기존의 일반 카메라렌즈로는 기가픽 셀 카메라를 구현할 수 없고 이를 구현하기 위해서는 전체 렌즈시스템의 수차를 회절한계성능이하로 최대한 줄여야 한 다는 것이다. (2) $120^{\circ} \times 50^{\circ}$ 화각의 기가픽셀 카메라를 구현 하기 위해서는 전방대물렌즈의 직경 $(A)$ 은 $60 \mathrm{~mm}$ 가 적당하 고 초점거리 $\left(f^{\prime}\right)$ 는 $84 \mathrm{~mm} \sim 168 \mathrm{~mm}$ 가 적절하다는 것이다. (3)전방의 대물렌즈는 공심렌즈가 되어야 한다. 이로부터 마 이크로 카메라렌즈의 모든 회전축은 광학적으로는 중심축과 동등한 조건이 된다. (4) $120^{\circ} \times 50^{\circ}$ 의 전체 화각 $(\mathrm{FOV})$ 은 최 소 98 개의 마이크로 카메라렌즈를 수용하기 위해 $9^{\circ} \times 6^{\circ}$ 로 분할된다. (5) $9^{\circ} \times 6^{\circ}$ 의 분할화각 $(\Delta(F O V))$ 을 수용해야하는 마이크로 카메라렌즈의 구경은 타원형이 되고 직경 $A_{m}\left(f^{\prime}\right)$ 는 $10.8 \times 7.7(84) \mathrm{mm} \sim 18.3 \times 13.6(168) \mathrm{mm}$ 로 주어진다. (6) 마이크로 카메라렌즈의 초점거리 $\left(f_{m}{ }^{\prime}\right)$ 는 $M=-1$ 일 때 $f_{m}{ }^{\prime}$ $\left(f^{\prime}\right)=7.6(84) \mathrm{mm} \sim 25.7(168) \mathrm{mm}$ 로 주어지고, $M=-1 / 2$ 일 때 $f_{m}{ }^{\prime}\left(f^{\prime}\right)=5.0(84) \mathrm{mm} \sim 17.1(168) \mathrm{mm}$ 로 주어진다.

이상과 같이 전체 렌즈시스템을 구조적으로 파악하고 큰 틀에서의 렌즈사양 값들을 결정하는 일은 렌즈설계에서 가 장 중요한 작업이자 고도의 경험이 필요한 작업이기도 하다. 말하자면, 미지의 광활한 지역에서 무작정 길을 찾는 방식과 지도와 나침반을 가지고 길을 찾는 방식 간의 차이로 비유할 수 있을 정도이다. 본 연구를 바탕으로 강력한 컴퓨팅 파워 와 함께 trial \& error 방식의 숙련된 최적설계를 진행해 나가 면 매우 효과적으로 우리가 원하는 상분할 방식의 기가픽셀 카메라 렌즈시스템을 구현할 수 있을 것으로 기대한다.

\section{감사의 글}

본 논문은 2013년도 한남대학교 교비학술연구비로 이루어 졌으며, 이에 감사드립니다.

\section{References}

1. D. J. Brady, M. E. Gehm, R. A. Stack, D. L. Marks, D. S. Kittle, D. R. Golish, E. M. Vera, and S. D. Feller, "Multiscale gigapixel photography," Nature 486, 386-389 (2012).

2. Wall Street Journal, "Next cameras come into view," June 21 (2012).

3. Chosunilbo, "Gigapixel camera of Duke university," June 21 (2012).

4. E. J. Tremblay, D. L. Marks, D. J. Brady, and J. E. Ford, "Design and scaling of monocentric multiscale imagers," Appl. Opt. 51, 4691-4702 (2012).

5. D. J. Brady and N. Hagen, "Multiscale lens design," Opt. Express 17, 10659-10674 (2009).

6. K. W. Hodapp, N. Kaiser, H. Aussel, W. Burgett, K. C. Chambers, M. Chun, T. Dombeck, A. Douglas, D. Hafner, J. Heasley, J. Hoblitt, C. Hude, S. Isani, R. Jedicke, D. Jewitt, U. Laux, G. A. Luppino, R. Lupton, M. Maberry, E. Magnier, E. Mannery, D. Monet, J. Morgan, P. Onaka, P. Price, A. Ryan, W. Siegmund, I. Szapudi, J. Tonry, R. Wainscoat, and M. Waterson, "Design of the Pan-STARRS telescopes," Astronomische Nachrichten 325, 636-642 (2004).

7. W. J. Smith, Modern Optical Engineering (McGraw-Hill Inc., NY, USA, 2001), Chapter 6.

8. E. Hecht, Optics (Addison Wesley, MA, USA, 2001), Chapter 4-6.

9. C.-S. Rim, "The design of telecentric lenses and fly-eye lenses by utilizing f $\theta$ formula," Korean J. Opt. Photon. (Hankook Kwanghak Hoeji) 24, 9-16 (2013).

10. H.-J. Kwon and C.-S. Rim, "Design of two-group zoom lens system with wide angle of view using global structure function," Korean J. Opt. Photon. (Hankook Kwanghak Hoeji) 20, 319-327 (2009).

11. S. S. Lee, Geometrical Optics (Kyohakyongusa, Seoul, Korea, 1985), Chapter 1-4.

12. D. L. Marks, E. J. Tremblay, J. E. Ford, and D. J. Brady, "Microcamera aperture scale in monocentric gigapixel cameras," Appl. Opt. 50, 5824-5833 (2011). 